\title{
Rectangular and Random Conductors: AC Losses Evaluations and Manufacturing Considerations
}

\author{
Eraldo Preci ${ }^{* 1,2}$, Giorgio Valente ${ }^{1,2}$, Anuvav Bardalai ${ }^{1,2}$, Tommaso Transi ${ }^{1,2}$, Tianjie Zou ${ }^{1,2}$, David \\ Gerada $^{1,2}$, Michele Degano ${ }^{1,2}$, Giampaolo Buticchi ${ }^{1,2}$, Christopher Gerada $^{1,2}$ \\ 1) PEMC Group, University of Nottingham, Nottingham, United Kingdom \\ 2) PEMC Group, University of Nottingham, Ningbo, China \\ * exxep1@nottingham.ac.uk
}

\begin{abstract}
This paper presents a comparison between hairpin and random distributed winding in electrical machines for automotive applications. Indeed, the overall performance of an electrical drive system is seriously affected by its winding design. The considered electrical machine has a peak power of $115 \mathrm{~kW}$ and a maximum operating speed of $12000 \mathrm{rpm}$. Both cost and manufacturing aspects are here discussed in detail. Two different machine topologies have been investigated and Finite Element Analysis (FEA) results are presented and discussed. Then, the comparison between hairpin and random winding configuration in terms of $\mathrm{AC}$ copper losses are presented for the selected geometry. The accurate AC losses estimation can be done by modelling each single conductor. In order to significantly reduce the simulation time, a domain model reduction has been adopted. Based on two different driving cycles, Urban Dynamometer Driving Schedule (UDDS) and Highway Fuel Economy Test (HWFET), the AC losses have been evaluated. The main outcome of this work is the considerable reduction of $\mathrm{AC}$ losses by using a segmented hairpin winding.
\end{abstract}

Index Term-AC losses, electrical machines, winding, high frequency, automotive, hairpin, random, segmented hairpin, manufacturing, mass production, UDDS, HWFET

\section{LIST OF SYMBOLS}

$p \quad$ - No. of pole pairs

$q$ - No. of slot per pole per phase

$E \quad-\quad$ Electric Field

$B$ - Flux Density

$t \quad$ - Time

$f \quad-\quad$ Frequency

$\sigma \quad-\quad$ Cooper conductivity

$\mu_{0}$ - Magnetic permeability in the vacuum

$R_{d c}-\quad$ DC resistance

$\Omega \quad-\quad$ Mechanical speed

\section{INTRODUCTION}

There is currently wide interest in the research and development of power traction applications driven by electrical machines. Ongoing efforts are fueled by the need for the new generations of "green" products, such as hybrid and electric vehicles. Governments and automotive industries are pushing their research programs to realize hybrid and pure electric powertrains for both automotive and aerospace, and in general for all transport applications. Challenging targets of $81 \mathrm{~g}$ of $\mathrm{CO} 2$ emission per $\mathrm{km}$ (fuel consumption of around 4.1 and $3.6 \mathrm{~L} / \mathrm{km}$ for petrol and diesel fuel, respectively [1]) will be compulsory for all new cars in Europe by 2025 .
Another important challenge in transportation industry is the maximization of the power density, in terms of power to volume $(\mathrm{kW} / \mathrm{L})$ or power to mass $(\mathrm{kW} / \mathrm{kg})$ ratios [2]. US Department Of Energy (DOE) has recently announced technical targets for light duty electric vehicles: in terms of power density, a target of $33 \mathrm{~kW} / \mathrm{L}$ for a $100-\mathrm{kW}$ traction drive system has to be reached by 2025 [3].

Nowadays, all power traction solutions for electric vehicles (EVs) are of ac type. The most common machine topologies for EVs are synchronous permanent magnet, synchronous wound field, induction and synchronous reluctance machines.

The electrical machine's performance are strongly dependent on the power loss generated as well as the thermal behavior, in particular the ability to dissipate as much as possible the resultant heat. At designing stage of high-power density, high-efficiency and high-speed electrical machines it is crucial to estimate accurately power losses and understand the thermal behavior of the machine. Copper loss in the winding is a major source of loss within an electrical machine. Copper loss can be subdivided into two basic components: frequency independent dc ohmic loss and high frequency ac effects. The dc ohmic power loss component is well understood and is possible to evaluate this analytically. In contrast, the ac winding power loss component is very complex to estimate analytically with an acceptable error. This is the reason why FEA is crucial in order to obtain a more accurate value for this specific component.

It is necessary to intensify the efforts in designing high-speed ac machines to increase power density. However, increasing the excitation frequencies aggravates the losses in the machine, such as the Iron and copper losses. In automotive applications, a typical electric/hybrid-electric vehicle propulsion motor can operate with fundamental frequency higher than $1 \mathrm{kHz}$. Therefore, AC losses cannot be neglected. Some preliminary considerations are needed to design the stator winding and rotor structure to improve the electrical machines performance [4],[5],[6].

An accurate ac power loss prediction has been acknowledged as an important element in the design process. This together with thermal analysis, allows the motor power output capability to be accurately evaluated at the design stage. Two principal themes emerge from a review of the literature focused to the subject of ac winding effects. The first is focused around developing and improving techniques for 
predicting ac winding loss effects [7]-[14]. The second utilizes the existing methods of deriving the ac winding loss in analysis and design/optimization of electrical machines, transformers and passive components [15]-[18].

Among the distributed winding used in industrial application there are different types of wires available in the market: Litz wires, round random winding and hairpin. Litz wires are normally used for very high frequency applications, and present some manufacturing disadvantages, such as complex shaping and impregnation, low fill factor achievable and high manufacturing costs [19]. It normally presents the best ac/dc ratio, compared with the conventional stranded wire. However, because of the high purchasing cost, it is not an optimum solution for mass production such as automotive sector, where the cost minimization is one of the key drivers. In low - voltage high - current applications with low number of turns, random wires with many parallel paths are often used [20], [21]. Consequently, high circulating currents are expected, if a proper transposition is not adopted. Transposition is a twisting in axial direction which allows to achieve more uniform field distribution for all conductors [14]. Hairpin winding allows to obtain an higher fill factor compared with the other two types, which increases the capability of carrying current, thus a higher peak output torque is available. A perfect transposition is possible. One of the cons is the lower degree of freedom in terms of turns in series per phase, as only few configurations are feasible and can be manufactured [20].

This paper aims to compare two different distributed winding solutions for the stator of a Permanent Magnet assisted Synchronous Reluctance (PMaSynRel) machine designed for automotive application: the hairpin and the random distributed wires. In section III the two driving cycles UDDS and HWFET are introduced and the prototype for the case study under analysis is described. While, in section IV the 2D FE model is introduced to accurately determine the AC losses, a model reduction is proposed in order to have the lowest computational time without affecting the accuracy. In section $\mathrm{V}$, the results of the analysis are presented, comparing in detail the losses calculated for different winding configurations. The evaluations are performed for a number of operating conditions for both driving cycles. Section VI summarizes the main outcomes of this work.

\section{MOTOR AND DRIVING CYCLES}

The target e-machine data considered for this work have been described below, in Table 1 .

Table 1

\begin{tabular}{cc}
\hline \multicolumn{2}{c}{ E-MACHINE DATA } \\
\hline \hline \\
\hline e-machine base speed & $6000 \mathrm{rpm}$ \\
e-machine max speed & $12000 \mathrm{rpm}$ \\
Power at base speed & $115 \mathrm{~kW}$ \\
Constant Power Speed Ratio & 2
\end{tabular}

First of all, a preliminary trade-off study has been completed, considering the following machine topologies: interior Permanent Magnet (IPM), Surface Mounted Permanent

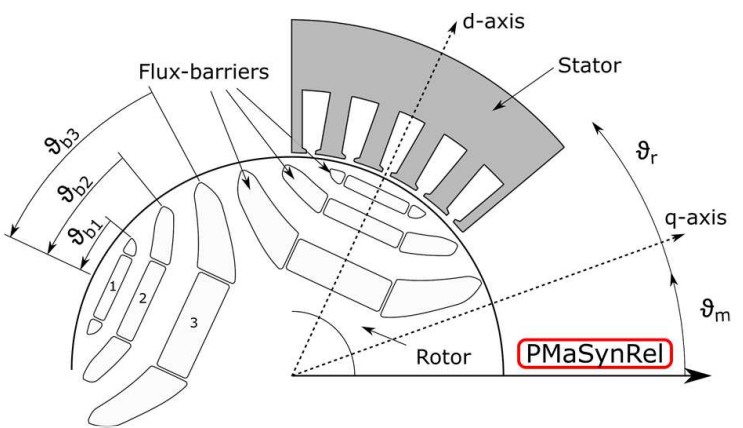

Figure 1: Permanent Magnet assisted SynRel motor sketch.

Magnet (SMPM), Synchronous Reluctance (SynRel) and Permanent Magnet assisted Synchronous Reluctance (PMaSynRel) machines.

After that, an optimization process has been carried out in term of costs and performance with ModeFrontier [22]; the PMaSynRel option with three barriers has been selected as the best candidate among the others in terms of wide fluxweakening capability, high torque density, efficiency and compactness. A PMaSynRel motor with 4 poles is considered in this paper, with two different slots per pole per phase (q) configurations: 2 and 4. The machine geometry is presented in Fig. 1 and the main geometrical parameters are reported in Table 2.

Table 2

\begin{tabular}{cc}
\hline & GEOMETRICAL PARAMETERS \\
\hline \hline Name & Description \\
\hline$\vartheta_{b 1}$ & Flux barrier angle 1 \\
$\vartheta_{b 2}$ & Flux barrier angle 2 \\
$\vartheta_{b 3}$ & Flux barrier angle 3 \\
$W_{s o}$ & Slot opening width \\
$h_{s}$ & Slot height \\
$W_{p m i}$ & Permanent Magnet width \\
$h_{p m i}$ & Permanent Magnet height
\end{tabular}

During the normal life of a vehicle, the motor will work on several operating points. According to [23] the motor performances are analysed on the basis of two driving cycles, UDDS and HWFET. In Figure 2 UDDS and HWFET operation points are presented over the motor electromechanical characteristic. The first three most used operation points in HWFET and UDDS have been considered in this analysis.

To satisfy the mission profile electrical machines are designed to cover the peak power and achieve maximum speed. As it is later presented in Section V, if the cooling system design is based only on maximal speed and base speed operating points, an overestimation of the entire cooling system will occur: this could lead to an oversized machine and an more expensive stator winding arrangement. For these reasons, it is crucial to consider the driving cycle of the motor in order to have a better estimation of the losses to allow a more accurate cooling system design. 


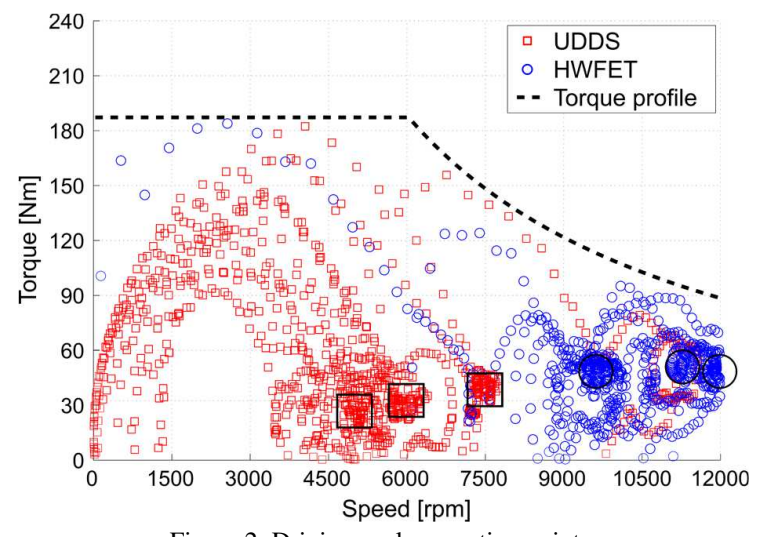

Figure 2: Driving cycle operating points.

According to the physical relations between mechanical and electrical speed as shown in (1), the fundamental frequency can be calculated as

$$
\mathrm{f}=\frac{\Omega \mathrm{p}}{60}
$$

Machine volts-ampere rating VA depends on DC-link voltage $V_{d c}$ and current rating $I_{N}$ of the inverter power module as shown in (2)

$$
V A=\frac{3 V_{d c}}{2 \sqrt{3}} I_{N}
$$

Once the machine is designed and fully characterized through flux maps, the Ampere-turns and phase current angles, necessary to satisfy the torque demand, MTPA, FW and MTPV constrains can be determined, as reported in Table 3. The preliminary machine analysis has been performed with one turn per slot per pole per phase. The number of turns is then adjusted depending on the available DC-link voltage $V_{D C}$.

Table 3

\begin{tabular}{cccc}
\hline \multicolumn{4}{c}{ Driving Cycle Operating points } \\
\hline \hline & $\begin{array}{c}\text { Torque } \\
{[\mathrm{Nm}]}\end{array}$ & $\begin{array}{c}\text { Speed } \\
{[\mathrm{rpm}]}\end{array}$ \\
\hline \hline \multirow{2}{*}{ Operating Point } & 1 & 28 & 5000 \\
& 2 & 30 & 6000 \\
& 3 & 40 & 7500 \\
\hline 5 & 4 & 50 & 9500 \\
5 & 5 & 55 & 11250 \\
& 6 & 50 & 12000
\end{tabular}

\section{2D FE MODEL}

A flexible tool has been developed in order to create the geometry and the winding topology at the strand level and finally to run a FEA using MagNet from Mentor Graphics. The environment in which the script operates is MATLAB. A mesh sensitivity analysis has been done. With a distributed winding, it is possible to adopt a model reduction to one pole. Rotor and stator yoke are made by SiFe M270-35A. The PMs that have been selected are NdFeB 28/23 type and the material used for windings is Copper with conductivity $5.77 \times 10^{7}$ Siemens/meter.

To achieve a better estimation of losses it is mandatory to take into account skin and proximity effect and circulating currents. For this purpose, a strand level FE model has been generated [24], as the one shown in Figure 4.

For this specific application, the DC-link voltage is set to 520 $\mathrm{V}$, generally this is in the range from $360 \mathrm{~V}$ to $700 \mathrm{~V}$ for this kind of application [20]. When operating at high currents and high frequency, the winding design requires the adoption of parallel paths, to form different bundles connected in series and/or in parallel.

To minimize the losses, it is necessary to displace the bundles into tangential direction to reduce the flux linked to the turns [25]. this is showed in Fig.5 where each bundle is associated with a different color. The sequence to make the coil is yellow, green, red, blue and so on. Since the phenomena are very sensitive to the frequency, two different solvers have been chosen: transient, which estimate all frequencies generated in the machine and then time harmonic, which consider only the fundamental frequency of the source.

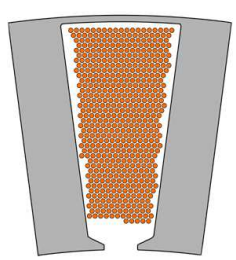

a)

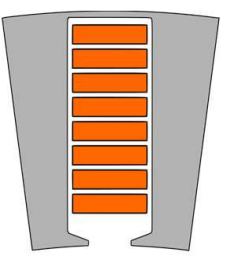

b)

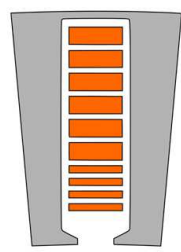

c)
Figure 4: Stranded models options: a) Random, b) Hairpin, c) Segmented Hairpin

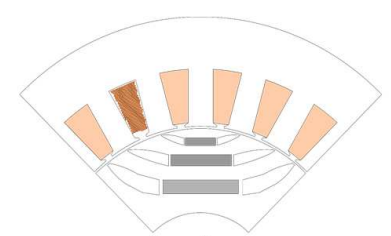

a)

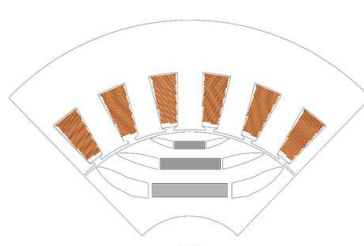

b) c)

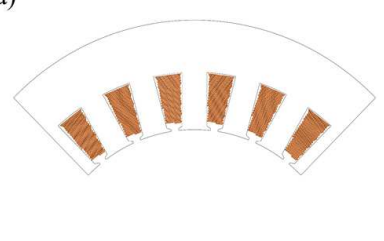

Figure 6: Simulation models: a) Model1, b) Model2, c) Model3 


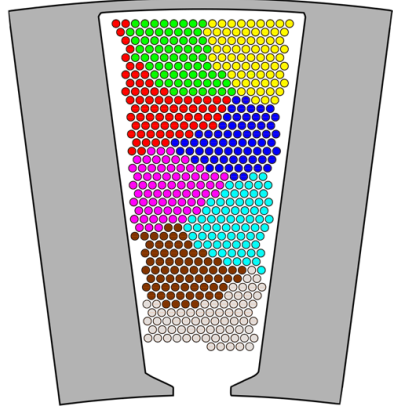

Figure 5: Random Winding Model.

A minimization FE model is done to reduce computational time without affecting significantly the result accuracy. As shown in Figure 2, three different models have been considered: Modell presents all slots modelled at strand level, Model 2 has only one slot modelled at the strand level and the other slots modelled as ideal stranded coil (losses estimated in one slot and multiplied by the number of slots) and Model 3 in which the same stator of Model 2 is analyzed without the rotor.

The same conditions in term of input (current source at the highest frequency) are set. Transient with motion simulation (T. w. M. ), transient and time harmonic (T. Harm.) simulations have been done for all models, as shown in Table 4, with T. Harm (Model3) simulations the computational time has been reduced by two orders of magnitude compared with T. w. M (Model1) and accuracy is very good. The PC used to run the simulations has a Quad Intel Xeon 3.5 GHz CPU and 32 GB RAM. Based on the foregoing considerations time harmonic Model3 is choose for subsequent analysis.
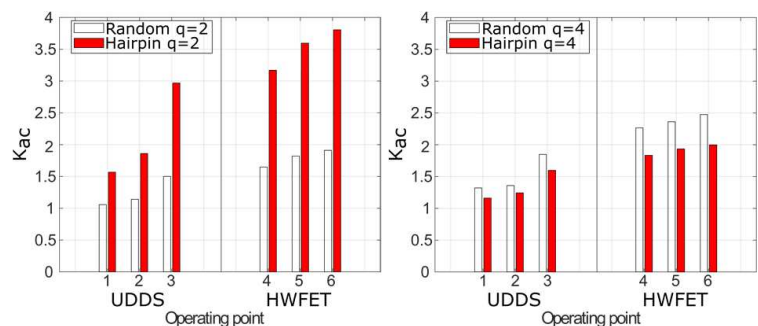

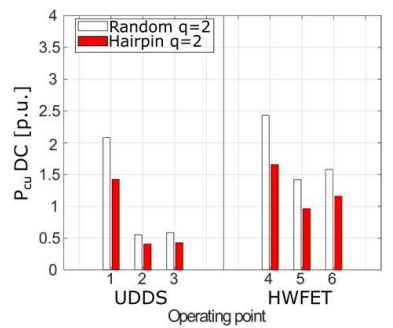

a)

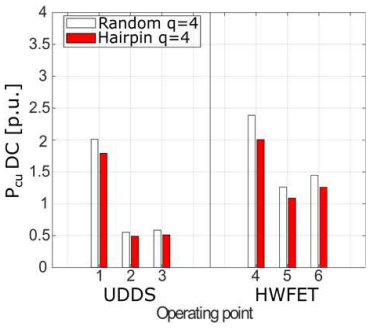

b)
Figure 7: Comparison between random hairpin; a) $\mathrm{q}=2$, b) $\mathrm{q}=4$.
Table 4

\begin{tabular}{cccc}
\hline \multicolumn{4}{c}{ MoDEL AND COMPUTATIONAL TIME REDUCTION } \\
\hline & $\begin{array}{c}\text { Elapsed time } \\
{[\mathrm{sec}]}\end{array}$ & $\begin{array}{c}\text { Losses } \\
{[\mathrm{W}]}\end{array}$ & No. of Elements \\
\hline \hline T. w. M. (Model1) & 14874 & 338.65 & 521446 \\
T. w. M. (Model2) & 1967 & 332.24 & 119692 \\
Transient (Model3) & 898 & 315.9 & 75862 \\
T. Harm. (Model3) & 119 & 326.4 & 75862
\end{tabular}

The total AC losses are given by:

$$
P_{A C}=P_{D C}+P_{\text {skin }}+P_{\text {prox }}+P_{\text {circ }}
$$

The first element on the right-hand side of (3) represents the DC losses and its relative resistance is analytically described as

$$
R_{D C}=\frac{n_{t u r n s} * \rho_{c u} * l_{s t k}}{A_{c u}}
$$

The DC losses can be reduced increasing the slot fill factor. The end winding length is estimated as

$$
l_{e w}=\frac{2.5 * D_{s i}}{p}
$$

where the inner stator diameter is

$$
D_{s i}=2 *\left(H_{b i}+g+R_{\text {int }}+h\right)
$$

Without significant loss in accuracy, $P_{\text {skin }}$ and $P_{\text {prox }}$ can be neglected in the end winding [26]. It is common to express the other elements of (3) with a dimensionless AC loss factor $K_{A C}$

$$
P_{A C}=K_{A C}(\eta) * P_{D C}
$$

$K_{A C}$ is function of the bore diameter $\mathrm{D}$ of the conductor (diameter for random and width and height for hairpin) normalized to the skin depth $\delta$.

$$
\eta=\frac{D}{\delta} ; \delta=\sqrt{\frac{1}{\sigma * f * \mu_{0}}}
$$

Considering the skin depth at maximum speed, a round conductor with diameter $0.8 \mathrm{~mm}$, has been identified as reasonable solution in term of costs and losses reduction. Hairpin bars have $3 \mathrm{~mm}$ height with $6.0 \mathrm{~mm}$ width for $\mathrm{q}=2$ and $2.5 \mathrm{~mm}$ height with $3.8 \mathrm{~mm}$ width for $\mathrm{q}=4$. It is possible to reduce the circulating currents through transposition. This can be expensive from a manufacturing point of view for random winding. On the other hand, for hairpin winding, 
transposition is needed otherwise very high circulating current will occur. According to [20], it is shown that a perfect transposition is possible. Most of the hairpin manufacturers are able to fit a maximum of 10 layers per slot. This configuration will be considered for the hairpin model. In Table 5 details about both types of windings are presented. Table 5

\begin{tabular}{ccc}
\hline & WINDING DETAILS & \\
\hline & $\begin{array}{c}\text { Random winding } \\
\mathrm{q}=2 / \mathrm{q}=4\end{array}$ & $\begin{array}{c}\text { Hairpin winding } \\
\mathrm{q}=2 / \mathrm{q}=4\end{array}$ \\
\hline \hline strand per slot & $416 / 208$ & $8 / 8$ \\
fill factor & $45 \% / 45.5 \%$ & $69 \% / 69 \%$ \\
number of turns & $16 / 8$ & $8 / 8$ \\
Strands in hand & $26 / 26$ & $1 / 1$
\end{tabular}

\section{RESUlts}

In this section $\mathrm{AC}$ losses evaluation for different machine topologies with Hairpin and Random winding is done. A per unit system is used, as a basis to compare the losses.

As mentioned before, assuming results given during maximum or base speed as key values for design, it could translate to wrong cooling system design. In Table 6 there are losses for these operative points for winding configurations considered, it is possible to do a prompt comparison with graphs below.

Table 6

\begin{tabular}{|c|c|c|}
\hline \multicolumn{3}{|c|}{ TOTAL LOSSES AT MAXIMUM AND BASE SPEED } \\
\hline Winding type & Base speed $[\mathrm{pu}]$ & Maximum speed[pu] \\
\hline Random $\mathrm{q}=2$ & 38.4 & 18.29 \\
\hline Random q=4 & 47.11 & 23.05 \\
\hline Hairpin $\mathrm{q}=2$ & 25.06 & 3.98 \\
\hline Hairpin $\mathrm{q}=4$ & 24.30 & 7.68 \\
\hline Hairpin seg. $q=4$ & 41.92 & 10.58 \\
\hline
\end{tabular}

Figure shows the copper losses for the machine with $q=2$ and $\mathrm{q}=4$, where both, random and hairpin winding are compared. Hairpin windings having higher fill factor present lower DC losses according to (4). Overall with $q=2$, the AC losses with hairpin are higher than random winding, with a difference of two times in HWFET. The contribution of the skin and proximity effects are very significant in this kind of configuration, nevertheless there is no circulating current, the $K_{A C}$ is almost double compared to the random winding.

Different trends were observed with $\mathrm{q}=4$. For hairpin winding the $\mathrm{AC}$ losses are lower because of the smaller cross section that causes a reduction in skin and proximity effect, leading to a reduction of $10 \%$ and $25 \%$ respectively in UDDS and in HWFET, compared to the random winding.

Conductors that are close to the slot opening, cause higher losses because affected by a bigger flux variation. For random winding is possible to avoid this effect by staying away from this area as much as possible. For hairpin winding, then, another option is possible: adopting a segmented layer for the last conductors in each parallel path, a reduction that spans from $12 \%$ up to $20 \%$ can be obtained as shown in Figure 9: Comparison between hairpin segmented and random.. In Figure 8: Comparison between hairpin and segmented hairpin. a comparison between the best configurations for the two winding topologies is presented, concluding that the best option to limit AC losses it is hairpin winding with the last layers segmented, since the total copper losses are lower for all operating points.

The final choice of the winding topology also depends from some manufacturing considerations. In Table 7 pros and cons of both topologies have been summarized.

Table 7

\begin{tabular}{ccc}
\hline & WINDING SUMMARY & \\
\hline & Random & Hairpin seg. \\
\hline \hline Total copper losses & $\mathrm{X}$ & $\mathrm{V}$ \\
Compactness & $\mathrm{X}$ & $\mathrm{V}$ \\
Flexibility & $\mathrm{V}$ & $\mathrm{X}$ \\
Repeatability & $\mathrm{X}$ & $\mathrm{V}$ \\
Automation & $\mathrm{X}$ & $\mathrm{V}$
\end{tabular}

\section{CONCLUSIONS}

In this paper $\mathrm{AC}$ losses evaluation for different winding solutions have been performed through a FEA. For the sake of the accuracy a strand level FE model has been made. Two different vehicle driving cycles (UDDS and HWFET) have been considered. The three most used points have been used for the AC loss estimation. A domain reduction and three different simulation models have been compared; it has been demonstrated that without affecting significantly the accuracy the simulation time can by reduced drastically, if an appropriate simulation model is selected. Two different machines have been studied, with number of slots per pole per phase equal to 2 and 4. Different trends have been achieved for random distributed winding and hairpin winding: using random winding topology, $\mathrm{AC}$ losses increase as q increase. In opposition, using hairpin winding topology, AC losses decrease as q increase. Finally, the segmented hairpin solution has been identified as a further improvement compared to the standard hairpin topology in terms of $\mathrm{AC}$ losses reduction: an additional reduction up to $20 \%$ in HWFET can be achieved for this case study. Taking into account the AC losses reduction and a favorable manufacturing process, segmented hairpin winding has marked advantages for the automotive applications in hand. 


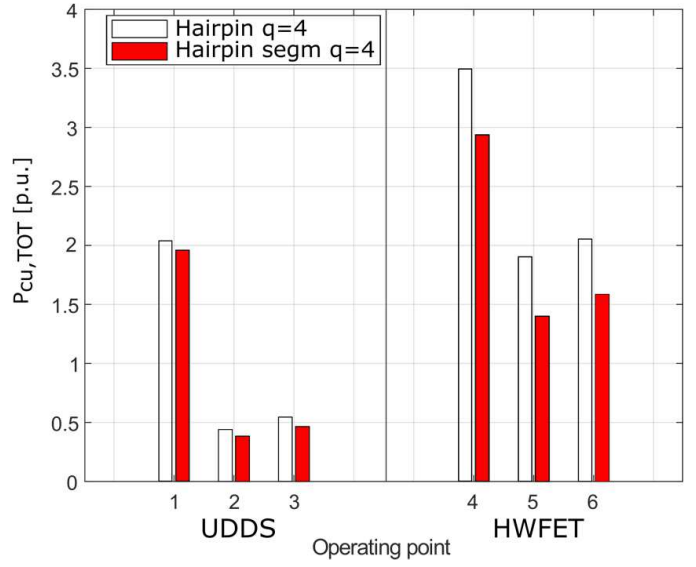

Figure 8: Comparison between hairpin and segmented hairpin.

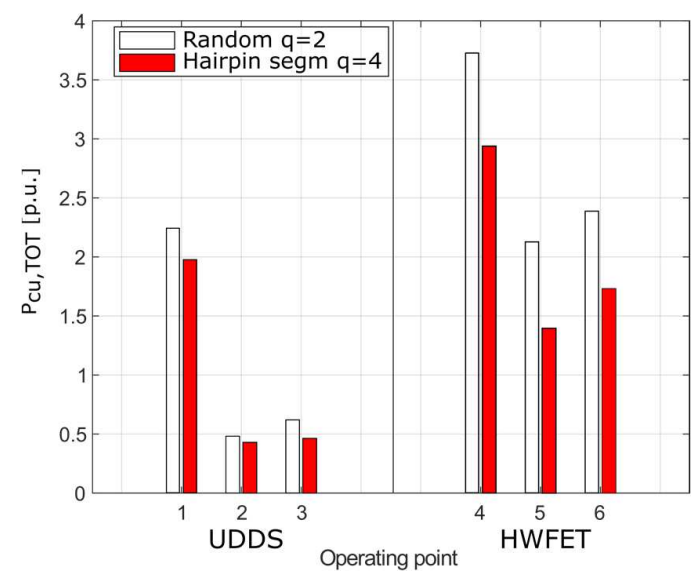

Figure 9: Comparison between hairpin segmented and random.

\section{REFERENCES}

[1] "The roadmap for transforming the EU into a competitive, lowcarbon economy by 2050," 2016. [Online]. Available: ec.europa.eu/ clima/sites/clima/

[2] V. Madonna, A. Walker, P. Giangrande, G. Serra, C. Gerada, and M. Galea, "Improved Thermal Management and Analysis for Stator EndWindings of Electrical Machines," IEEE Transactions on Industrial Electronics, vol. 66, pp. 5057-5069, 2019.

[3] "Electrical and Electronics Technical Team Roadmap," [Online]. Available:

https://www.energy.gov/sites/prod/files/2017/11/f39/EETT\%20Ro admap\%2010-27-17.pdf, Accessed on: Dec. 12, 2018.

[4] Wrobel, D. Staton, R. Lock, J. Booker and D. Drury, "Winding Design for Minimum Power Loss and Low-Cost Manufacture in Application to Fixed-Speed PM Generator," in IEEE Transactions on Industry Applications, vol. 51, no. 5, pp. 3773-3782, Sept.-Oct. 2015.

[5] S. Nuzzo et al., "A Methodology to Remove Stator Skew in SmallMedium Size Synchronous Generators via Innovative Damper Cage Designs," in IEEE Transactions on Industrial Electronics, vol. 66, no. 6, pp. 4296-4307, June 2019

[6] D. Fallows, S. Nuzzo, A. Costabeber and M. Galea, "Harmonic reduction methods for electrical generation: a review," in IET Generation, Transmission \& Distribution, vol. 12, no. 13, pp. 31073113, 3172018.

[7] P. L. Dowell, "Effects of eddy currents in transformer windings," Proc.IEE, vol. 113, no. 8, pp. 1387-1394, Aug. 1966.
[8] J. A. Ferreira, "Improved analytical modeling of conductive losses in magnetic components," in IEEE Transactions on Power Electronics, vol. 9, no. 1, pp. 127-131, Jan. 1994.

[9] R. P. Wojda and M. K. Kazimierczuk, "Analytical optimization of s olidround-wire windings," IEEE Trans. Ind. Electron., vol. 60, no. 3, pp. 1033-1041, Mar. 2013

[10] M. M. Liwschitz-Garik, "Computation of skin effect in bars of squirrelcage rotors," Trans. Amer. Inst. Elect. Eng. Part III, Power App. Syst.,vol. 74, no. 3, pp. 768-771, Jan. 1955.

[11] A. Reatti and M. K. Kazimierczuk, "Comparison of various methods for calculating the AC resistance of inductors," IEEE Trans. Magn., vol. 38, no. 3, pp. 1512-1518, May 2002.

[12] T. Lubin, S. Mezani, and A. Rezzoug, "Analytical calculation of eddy currents in the slots of electrical machines: application to cage rotor induction motors," IEEE Trans. Magn., vol. 47, no. 11, pp. 4650-4659, Nov. 2011

[13] L. J.Wu, Z. Q. Zhu, D. Staton, M. Popescu, and D. Hawkins, "Analytical model of eddy current loss in windings of permanentmagnet machines accounting for load," IEEE Trans. Magn., vol. 48, no. 7, pp. 2138-2151, Jul. 2012.

[14] P. B. Reddy and T. M. Jahns, "Analysis of bundle losses in high speed machines," The 2010 International Power Electronics Conference ECCE ASIA -, Sapporo, 2010, pp. 2181-2188.

[15] P. D. Evans, W. M. Chew, "Reduction of Proximity Losses in Coupled Inductors," IEE Electric Power Applications, vol. 138, pp.51-58, 1991.

[16] T. Mizuno, S. Enoki, T. Asahina, T. Suzuki, M. Noda, H. Shinagawa, "Reduction of Proximity Effect in Coil Using Magnetoplated Wire," IEEE Transactions on Magnetics, vol. 43, pp. 2654-2656, June 2007.

[17] A. Van den Bossche, V. C. Valchev, S. T. Barudov, "Practical Wide Frequency Approach for Calculating Eddy Current Losses in Transformer Windings," IEEE International Symposium on Industrial Electronics, 2006, pp. 1070-1074.

[18] M. Sippola, R. E. Sepponen, "Accurate Prediction of HighFrequencyPower-Transformer Losses and Temperature Rise," IEEE Transactions on Power Electronics, vo. 17, pp. 835-847, September 2002.

[19] P. Mellor, R. Wrobel and N. Simpson, "AC losses in high frequency electrical machine windings formed from large section conductors," 2014 IEEE Energy Conversion Congress and Exposition (ECCE), Pittsburgh, PA, 2014, pp. 5563-5570.

[20] N. Bianchi and G. Berardi, "Analytical Approach to Design Hairpin Windings in High Performance Electric Vehicle Motors," 2018 IEEE Energy Conversion Congress and Exposition (ECCE), Portland, OR, 2018, pp. 4398-4405.

[21] P. Giangrande, A. Galassini, S. Papadopoulos, A. Al-Timimy, G. L. Calzo, M. Degano, C. Gerada and M. Galea, "Considerations on the Development of an Electric Drive for a Secondary Flight Control Electromechanical Actuator," IEEE Transactions on Industry Applications, vol.55, no. 4, pp. 3544-3554, 2019.

[22] Clarich, Alberto, R. Russo, and M. Carriglio. "Multi-objective optimization with modefrontier interfaces for ansa and metapost." 4th ANSA \& $\mu$ ETA International Conference. Thessaloniki, Greece. 2011

[23] M. Degano, E. Carraro and N. Bianchi, "Robust optimization of a traction PMASR motor according to given driving cycles," 2014 International Conference on Electrical Machines (ICEM), Berlin, 2014, pp. 270-276.

[24] A. Bardalai et al., "The Influence of Strands and Bundle-Level Arrangements of Magnet Wires on AC Losses in the Winding of High - Speed Traction Machine," 2018 21st International Conference on Electrical Machines and Systems (ICEMS), Jeju, 2018, pp. 65-69.

[25] D. Bauer, P. Mamuschkin, H. Reuss and E. Nolle, "Influence of parallel wire placement on the AC copper losses in electrical machines," 2015 IEEE International Electric Machines \& Drives Conference (IEMDC), Coeur d'Alene, ID, 2015, pp. 1247-1253.

[26] H. Hämäläinen, J. Pyrhönen and J. Nerg, "AC Resistance Factor in One-Layer Form-Wound Winding Used in Rotating Electrical Machines," in IEEE Transactions on Magnetics, vol. 49, no. 6, pp. 2967-2973, June 2013. 